\title{
Applying Lean Techniques to Improve the Patient Scheduling Process
}

\author{
Edward M. Wojtys, MD, Laurie Schley, Kristi A. Overgaard, BSc, Julie Agbabian, MS, ATC
}

\begin{abstract}
A patient's access to healthcare resources often begins with scheduling an appointment with a medical doctor or other provider. An inefficient scheduling system leads to unnecessary delays in providing care for patients and frustration for referring

physicians. We used the tools of lean thinking to evaluate our current scheduling system, remove wasteful processes and procedures, and implement a more efficient and effective system. In doing so, we increased the value for our patients, who benefit from more timely access to care and greater satisfaction.
\end{abstract}

\section{Keywords \\ lean thinking \\ operational efficiency patient scheduling}

Journal for Healthcare Quality Vol. 31, No. 3, pp. 10-16 (c) 2009 National Association for Healthcare Quality
Healthcare resources are in great demand. Patients often have to wait long periods of time before being seen by physicians or other medical providers. It is easy to assume that this is now just a fact of life and that there is little we can do to change things. However, a careful examination of the processes that we take for granted can reveal powerful opportunities to improve the waste and inefficiencies that are so frustrating for patients, employees, and medical providers.

The process of scheduling patients in a medical specialty clinic is of vital importance to the patient and practitioner. Often, this contact forms the basis of the patient's first impression of a facility and provider. Patients want to be seen promptly by physicians or other providers who are familiar with their diagnoses or problems, while practitioners want a system capable of efficiently triaging patients. The intermediaries between the patient and the practitioner are the schedulers or the clinic coordinator. These individuals must be sympathetic, capable, and flexible as they interact with patients or referring physicians. Furthermore, they require the tools and autonomy in order to meet the needs of individual patients and schedule them in the correct clinic or with the most appropriate provider. Providers and patients rely on this system to be efficient and cost-effective, yet, in many cases, it is not. A review of patient satisfaction surveys from our outpatient sports medicine clinic revealed that many of our patients were dissatisfied with our scheduling system and experienced long delays in scheduling. The providers felt that the system suited their needs and functioned quite well; they did not realize how inefficient it was. Our patients' concerns provided the impetus for us to review and improve our scheduling process. We used the principles of lean thinking (Womack \& Jones, 2003) to accomplish this.

\section{Overview of Lean Thinking}

Lean thinking is an operational improvement philosophy derived from the automobile manufacturing industry (Liker, 2004). It is a framework for efficiently providing customers with exactly what they want through continuous improvement of the production process. Optimizing the production and delivery of a product or service is the focus of the lean process. The fundamental concepts involved in creating a lean process are value, flow, pull, and perfection (Womack \& Jones, 2003). The first and most critical step toward establishing a lean production process is to identify precisely what the customer values. This should be a specific product or service and can only be defined by the customer. Next, every step in production of this product or service is illustrated in what is termed the value stream. The value stream is used to identify and eliminate waste, which includes anything within the process that is of no value to the customer, with the aim of creating an efficient production flow. Ideally, the customer is able to pull the value from the process without unnecessary effort or delay. The result is a product or service that is as close as possible to what the customer actually wants. The lean process is an unending cycle toward perfection, in which the production of a product or service is continually refined and improved.

Lean thinking has been applied successfully in a variety of industries. There are a number of reports of its application in healthcare (Bush, 2007; Endsley, Magill, \& Godfrey, 2006; Kim, Spahlinger, Kin, \& Billi, 2006; Young et al., 2004).

\section{Creation of the Lean Process}

In our patient scheduling process, the consumers are the patients, referring physicians, and medical providers. We determined what our customers value from their comments and suggestions, as well as from our own experience as 
healthcare consumers and medical professionals. Patients and referring physicians value prompt access to appropriate medical providers, while medical providers value an efficient system that accurately triages patients to their clinics.

Once this value was identified, a current state value stream map (CS VSM) was created (Rother \& Shook, 2003). The mapping process required detailing all the steps and information flow in the current patient scheduling process. For our patient scheduling, the CS VSM included capturing patient and insurance information, previous medical records, test results, and imaging films that were collected by the clinic coordinator before an appointment was scheduled (Figure 1). In many cases, a physician's clinical expertise and review was thought to be necessary. In addition to illustrating the individual steps, the CS VSM identified who was responsible for each step, the technology used in the process, how the process flowed from one step to the next, the process time, and the wait times within and in between each step. In addition, duration of the entire process (total lead time) and how each step affects upstream and downstream processes were displayed. The resulting visual representation dramatically demonstrated just how inefficient our scheduling process was.

After discovering the minimal value that the delay in scheduling produced, the decision to streamline the process was readily agreed upon by providers and administrators. Even those practitioners who thought the scheduling system functioned well before the process was mapped now believed that it needed to be changed. We realized that the old system was continued for years because those involved were only aware of their individual components; they never saw the "big picture." The mapping process allowed us to visualize the big picture.

The information from the CS VSM was analyzed by a process improvement team, which included representatives of all stakeholders in the process. This team brainstormed ideas and identified specific steps in the process that could be eliminated or consolidated, so waste could be minimized and value maximized. After working through the process with a more efficient flow, a future state VSM (FS VSM) was created to visualize the new process (Rother \& Shook, 2003) (Figure 2). Our goal was to schedule at least $90 \%$ of our patients during the first phone contact. A major component of this improvement process included enabling schedulers and the clinic coordinator. They needed the autonomy to schedule patients without seeking other approvals. In order to help the schedulers assign patients to the correct providers, thereby increasing value for the customers, the clinic coordinator and physicians designed algorithms based on clinical problems that the schedulers were likely to encounter (Figure 3). These algorithms were used by the call center to identify provider preferences and the types of injuries and conditions they treat.

Implementation of the lean process was completed in only 10 days. During this time, we introduced the lean process to staff, finetuned the clinical algorithms for schedulers, and worked to enable the call center to schedule appointments without pre-approval. After implementation, a mindset of continual improvement and elimination of waste was essential to maintain the lean process. Continual feedback from the providers and patients to the schedulers is needed to ensure the continued maximal value for all our customers.

\section{Results of Thinking Lean}

Scheduling patient appointments in our old system sometimes took as little as 5 minutes on the phone. However, it took up to 36 days for some patients, requiring up to 21 phone contact minutes between the patient and the scheduler. Even more alarming was the realization that the lengthy physician review of medical records and images only added value for approximately $10 \%$ of our patients.

During the first month after implementation of the lean process, 454 patients contacted our clinic by telephone. Of these, $305(67 \%)$ were appropriate for our sports medicine practice and were scheduled during the initial call, with an average phone contact time of 2.5 minutes. In all, $339(75 \%)$ patient requests for appointments were managed with one phone call. Of those not managed on the first call, the most common reasons were either unique injuries/ conditions or out of network insurance. Those patients who did not match our physicians' specialized practice parameters were referred to other orthopedic services who could more appropriately meet their needs. With regard to those patients with out network insurance, we recommended that they contact their primary care physician or work with their insurance 


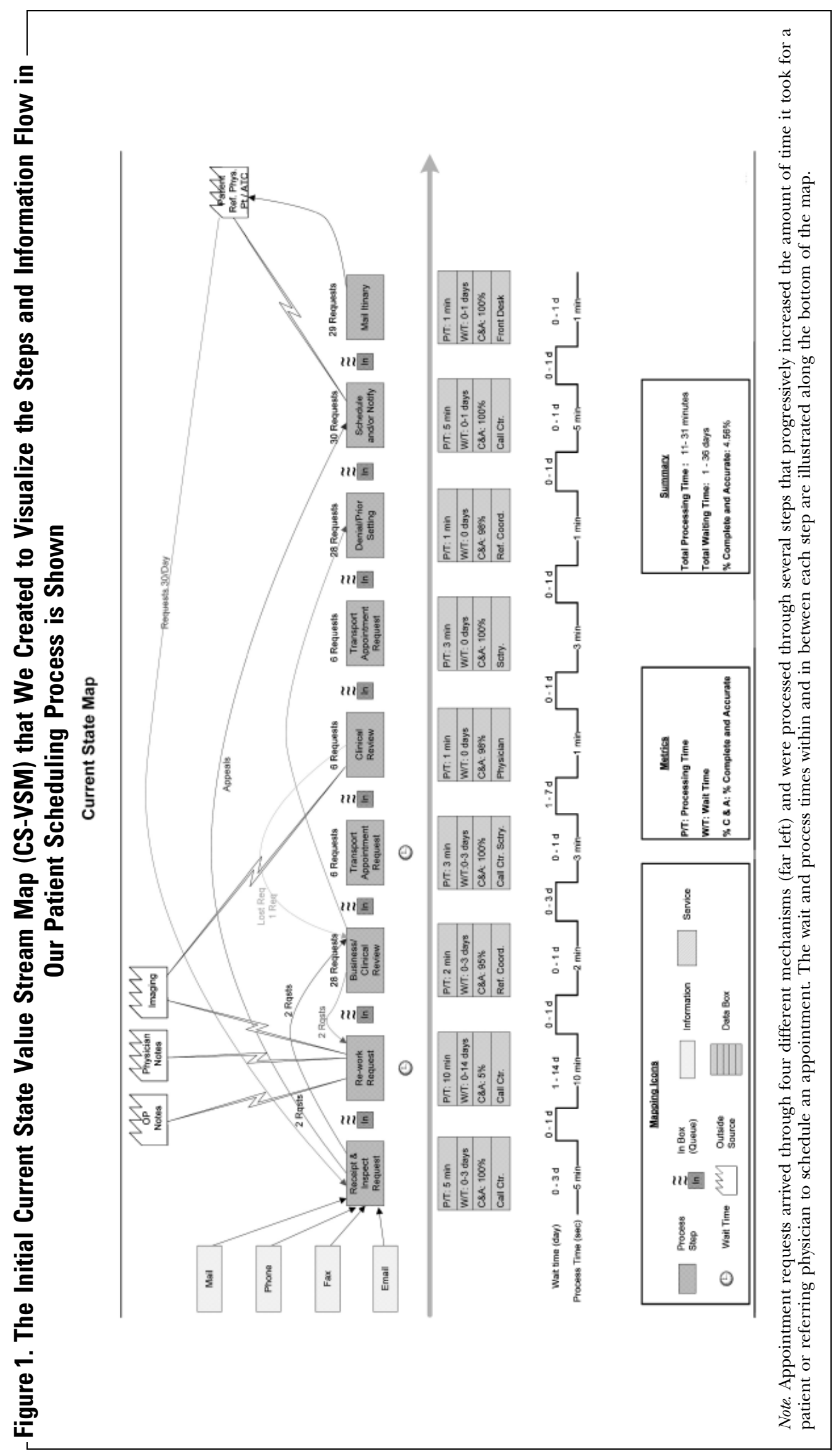




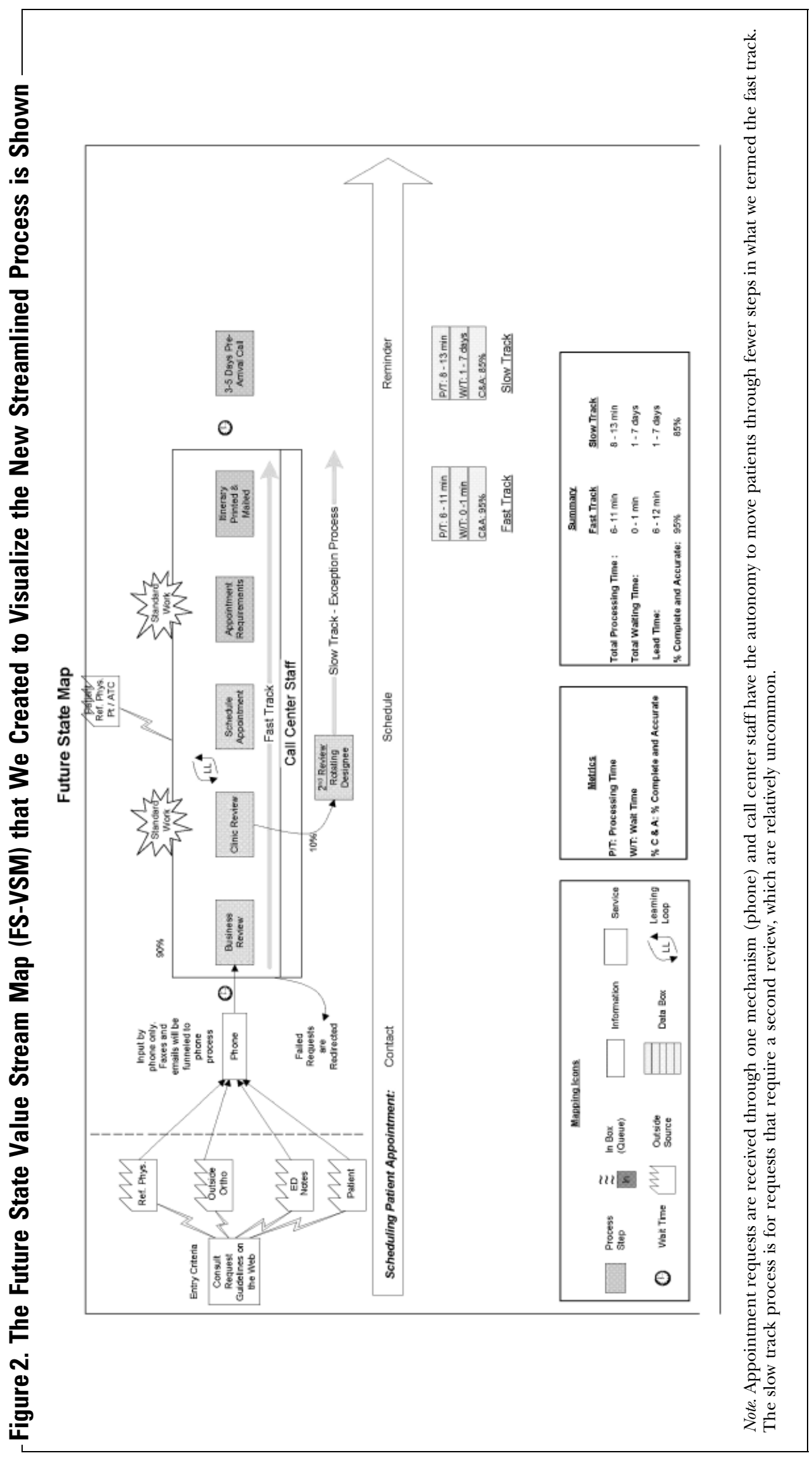




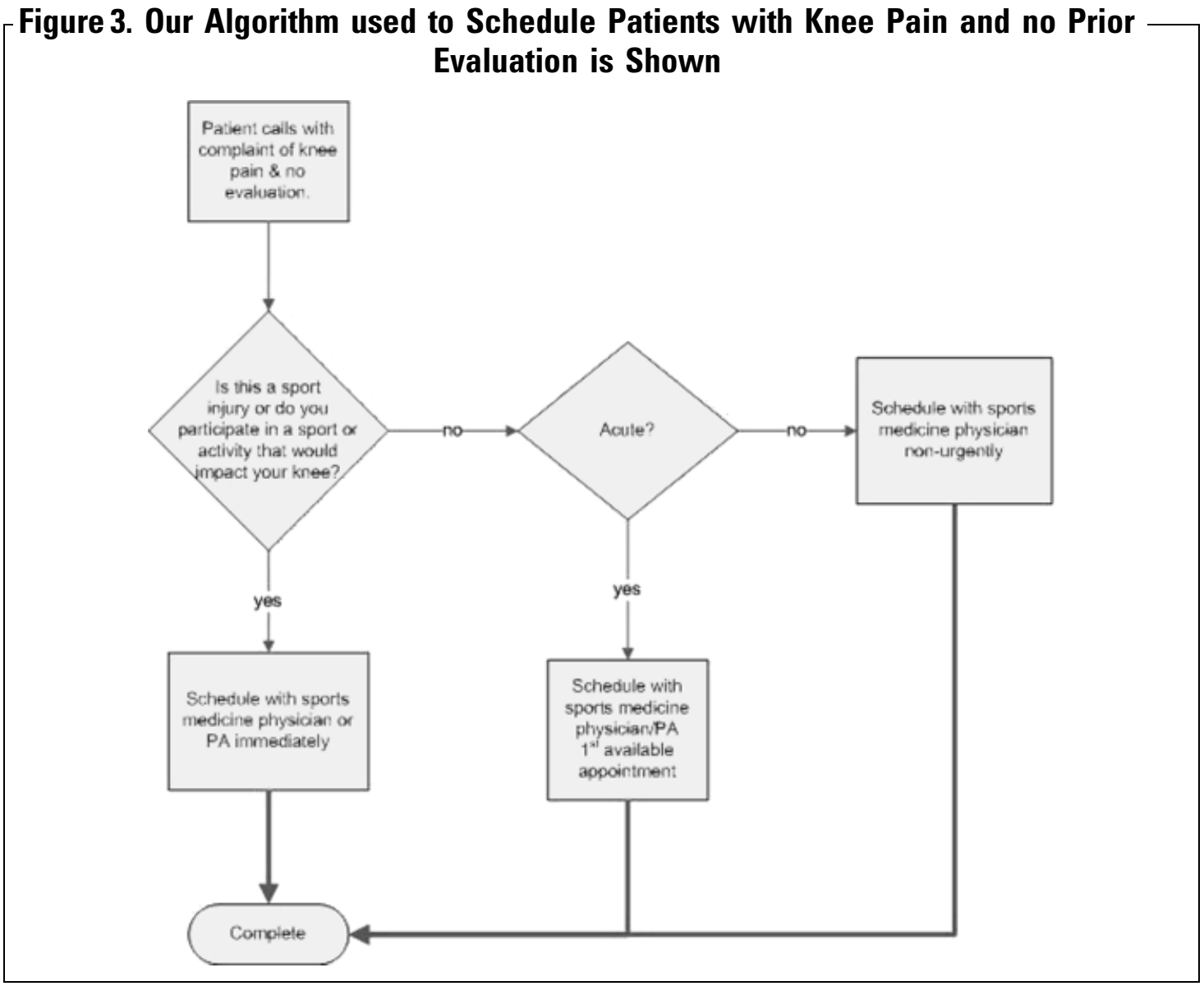

company directly to avoid large out of pocket expenses.

During the second month, 450 patients contacted us by telephone. Of these, $315(70 \%)$ patients were scheduled with one call, averaging 2.5 minutes per call. We were able to increase the number of requests managed with one call to $356(79 \%)$. In the third month, 547 patients contacted us by telephone. Of these, $388(71 \%)$ patients were scheduled with one call. We maintained the average 2.5 minutes per call and the number of requests managed with one call was $430(79 \%)$. At 6 months, 435 of $535(81 \%)$ patients were scheduled with one call; we managed $474(89 \%)$ of all patient appointment requests with one call, while maintaining the 2.5-minute average call duration. After 14 months, 392 of $517(76 \%)$ of patients were scheduled with one call, while $432(84 \%)$ patient appointment requests were managed with one call. We continue to maintain the 2.5-minute average call time.

Two months after making the lean improvements to our scheduling system, we requested verbal and e-mail feedback from patients, staff, and referring clinics. Our patients liked being scheduled promptly for appointments. Feedback on the lean improvements from our referral sources was extremely positive. When our new scheduling process was presented to a managed care liaison service between primary care physicians and specialty clinics, they were eager to help us implement the changes. They felt that the changes we made also helped them streamline their process. A notification was sent to all the primary care physicians in our system to inform them that we only accepted telephone referrals. This allowed us to answer questions immediately and eliminated repeated return phone calls for information, which saved everyone time.

The value of this process for the referring physicians became evident as it reduced their paperwork and the need to make repetitive calls due to scheduling delays for appointment requests on behalf of their patients. Our call center staff enthusiastically adopted the new process, and supported it with a positive outlook as they were empowered to do their job more efficiently and help patients directly. 


\section{Discussion}

The concept of lean thinking can be used to identify opportunities to create change with real value in the healthcare setting. We used lean thinking techniques to improve the efficiency of the patient scheduling system in our outpatient sports medicine clinic. The evaluation of our scheduling process revealed a system that was overburdened by unnecessary steps and procedures, resulting in waste of valuable resources that directly affected our patients. Our patient satisfaction has improved, our referral network is pleased, and our employee satisfaction has improved dramatically as well. The call center now feels empowered and the providers have seen few associated problems.

While our original goal was to schedule $90 \%$ of our patients during the first phone contact, we found that, realistically, after 6 months we were able to sustain a little more than $85 \%$ rate overall due to the complexity of some of the cases we encounter in our health system. After demonstrating our ability to maintain this performance on a monthly basis for the first 9 months, we began semi-annual reviews, and now monitor the process annually to ensure that the process stays lean. Although a process-wide review occurs each year, a lean mindset persists as employees confront ongoing challenges in the sometimes complicated patient scheduling process. Unfamiliar problems regularly surface and often require adjustments in our protocols. Patient satisfaction surveys are used to assess improvement in customer service.

While we typically do not view our healthcare operations from a manufacturing perspective, the lean tools and processes pioneered in the automotive industry are applicable in the healthcare system. By using the lean thinking process, we were able to reduce waste and create an efficient, effective scheduling system that provides value to our patients, staff, and providers alike.

\section{Acknowledgments}

The authors gratefully acknowledge Debi Zahn and Dr. David Spahlinger for enabling the operational change we have described, Philippe Sammour for preparing the illustrations of the value stream maps, and Virginia O'Reilly and Silvana Janevski for implementing the new system in the call center.

\section{References}

Bush, R. W. (2007). Reducing waste in US health care systems. JAMA, 297(8), 871-874.

Endsley, S., Magill, M. K., \& Godfrey, M. M. (2006). Creating a lean practice. Family Practice Management, 13(4), 34-38.

Kim, C. S., Spahlinger, D. A., Kin, J. M., \& Billi, J. E. (2006). Lean health care: What can hospitals learn from a worldclass automaker? Journal of Hospital Medicine, 1(3), 191199.

Liker, J. K. (2004). The Toyota way (1st edition). Madison, WI: McGraw-Hill.

Rother, M., \& Shook, J. (2003). Learning to see, value-stream mapping to create value and eliminate muda (1.3 edition). Brookline, MA: The Lean Enterprise Institute Inc.

Womack, J. P., \& Jones, D. T. (2003). Lean thinking, banish waste and create wealth in your corporation (2nd edition). New York: Free Press.

Young, T., Brailsford, S., Connell, C., Davies, R., Harper, P., \& Klein, J. H. (2004). Using industrial processes to improve patient care. British Medical Journal, 328, 162-164.

\section{Authors' Biographies}

Edward M. Wojtys, MD, is a Professor in the Department of Orthopaedic Surgery and Chief of the Department's Sports Medicine service at the University of Michigan, Ann Arbor. $H e$ is the Medical Director of the university's MedSport facility, where the operational change we described was instituted. He participated substantially in the development of the operational change and to the conception and revision of the submission.

Laurie Schley is the Clinic Office Manager for MedSport at the University of Michigan, Ann Arbor. She participated substantially in the development of the operational change and to the conception, formulation, drafting, and revision of the submission.

Kristi A. Overgaard, BSc, is the Senior Editor in the Department of Orthopaedic Surgery at the University of Michigan, Ann Arbor. She contributed substantially to the research, formulation, drafting, and revision of the submission.

Julie Agbabian, MS, ATC, is the Operations Manager for MedSport at the University of Michigan, Ann Arbor. She participated substantially in the development of the operational change and to the conception, formulation, drafting, and revision of the submission.

For more information on this article, contact Laurie Schley atlbschley@med.umich.edu.

Journal for Healthcare Quality is pleased to offer the opportunity to earn continuing education (CE) credit to those who read this article and take the online posttest at http:// www.nurseslearning.com/courses/make_ test2.cfm?CourseKey=4592. This continuing education offering, JHQ 215, will provide $1 \mathrm{CE}$ hour to those who complete it appropriately.

\section{Core CPHO Examination Content Area}

II. Information Management 


\section{Objectives}

By participating in this independent study offering, the reader will be able to

1. Identify the 4 fundamental concepts of lean thinking

2. Describe how lean thinking was applied to a medical scheduling process

3. Recognize waste in a process

\section{Questions}

1. Who determines what is of value in the lean process?
a. The provider
b. The customer
c. The market
d. The hospital

2. Which of the following is not waste?
a. A redundant step
b. An unnecessary approval
c. Duplicating work
d. Anything that adds value

3. What do patients value in a scheduling process?

a. Going through several steps

b. Scheduling an appointment quickly

c. Having to repeat information

d. Obtaining medical documents

4. The value stream represents the lean concept of

a. Flow

b. Perfection

c. Pull

d. Importance

5. Perfection in a lean process refers to

a. An unachievable goal

b. Continued improvement c. The end point of lean thinking

d. Value

6 . The current state value stream illustrates

a. Only what brings value to a process

b. Only problems in the current process

c. The flow of the current process

d. Only what the customer values

7. The future state value stream map illustrates

a. Only problems in the current process

b. Only what brings value to a process

c. An improved process after waste is eliminated

d. Only what the customer values

8. The purpose of the current state value stream map is to

a. Identify waste

b. Add redundancy

c. Identify value

d. Identify where new staff is needed

9. In the patient scheduling process, who is not considered a customer
a. Patient
b. Medical provider
c. Referring physician
d. The insurance company

10. Where did lean thinking originate?

a. Healthcare industry

b. Automobile manufacturing industry

c. Food production industry

d. Computer industry 